\title{
Status and Future Directions of the ENERgy Star Program
}

\author{
Rich Brown, Lawrence Berkeley National Laboratory \\ Carrie Webber, Lawrence Berkeley National Laboratory \\ Jon Koomey, Lawrence Berkeley National Laboratory
}

\begin{abstract}
In 1992 the U.S. Environmental Protection Agency (EPA) introduced ENERGY STAR $^{\circledR}$, a voluntary labeling program designed to identify and promote energy-efficient products, in order to reduce carbon dioxide emissions. Since then EPA, now in partnership with the U.S. Department of Energy (DOE), has expanded the program to cover nearly the entire buildings sector, spanning new homes, commercial buildings, residential heating and cooling equipment, major appliances, office equipment, commercial and residential lighting, and home electronics.

This paper provides a snapshot of the ENERGY STAR program in the year 2000, including a general overview of the program, its accomplishments, and the possibilities for future development. First, we describe the products that are currently eligible for the ENERGY STAR label and the program mechanisms that EPA and DOE are using to promote these products. Second, we illustrate selected milestones achieved in some markets, and ways that EPA and DOE are responding to challenges or changes in certain markets. Third, we discuss the evolving ENERGY STAR brand strategy. Next, we explore ways in which ENERGY STAR interacts with and enhances other policies, such as appliance standards and regional market transformation collaboratives. We then discuss evaluation studies that EPA and DOE are undertaking to quantify the impact of the ENERGY STAR program. Finally, we discuss future areas of expansion for the ENERGY STAR program, including labeling of new products and integrated programs for commercial and existing residential buildings.
\end{abstract}

\section{The Energy Star Labeling Program}

This paper presents an overview of the ENERGY STAR ${ }^{\circledR}$ labeling program, operated jointly by the U.S. Environmental Protection Agency (EPA) and the U.S. Department of Energy (DOE). These agencies enter agreements with program partners that allow the partners to promote products meeting certain energy-efficiency and performance criteria through use of the ENERGY STAR label. As the program is voluntary by design, partnerships are critical to the success of ENERGY STAR. EPA and DOE have focused their efforts in areas where efficiency improvements can be achieved cost-effectively, while offering the same or improved level of service (the ENERGY STAR label does not constitute an endorsement of the product by EPA or DOE). The mission of the ENERGY STAR program is to realize significant reductions in emissions and energy consumption by permanently transforming markets for energy-consuming products so that energy-efficient products are the norm. At its core, ENERGY STAR is an information and branding campaign, intended to make it easy for consumers to identify and purchase energy efficient products. ${ }^{1}$ The goal of the program is to

\footnotetext{
${ }^{1}$ The program also works with industries to seek out new opportunities where energy-efficient technologies are not available in the market, such as was the case for TVs, VCRs, and computers.
} 
have widespread identification of the ENERGY STAR brand with the concepts of environmental protection and energy bill savings.

The EPA launched the ENERGY STAR program in 1992 with computers, monitors and printers. The goal was to promote energy-saving features already common in laptop computers for use in desktop devices. In 1995, fax machines, copiers, residential heating and air conditioning equipment, thermostats, new homes, commercial buildings, and exit signs were added to the labeling program. In 1996, DOE agreed to work jointly with EPA to promote energy efficient products using the ENERGY STAR logo. The DOE/EPA partnership was an important step in developing and expanding ENERGY STAR, because of DOE's depth of experience in developing and promoting energy efficient technologies. DOE introduced ENERGY STAR labels for refrigerators, room air conditioners, clothes washers and dishwashers. Scanners, multi-function devices and residential lighting fixtures were added to EPA's labeled products in 1997, followed by TVs and VCRs in 1998. DOE introduced an ENERGY STAR label for windows in 1998 and for screw-in compact fluorescent lamps in 1999. The ENERGY STAR label now covers 31 consumer product categories (U.S. EPA 2000). EPA and DOE continue to research products and industries in search of new program opportunities, as well as update the program specifications for existing products as needed. Factors evaluated include the potential for improvements in unit energy savings, the size of the stock, turnover rates, the receptiveness of the industry, and the visibility of the product with consumers.

EPA and DOE undertake many different types of program activities to promote ENERGY STAR products. These efforts are tailored to the particular markets for each product, and can include any of the following: 1) management and promotion of the overall ENERGY STAR brand; 2) setting and updating efficiency specifications for specific products, in conjunction with market players; 3) collaboration with other national, regional, state, and local energy efficiency programs; 4) contractor and builder sales training; 5) developing and disseminating information about energy efficient products for consumers and product endusers; 6) arranging preferred financing for ENERGY STAR-compliant products; and 7) developing software tools to help purchasers understand the benefits of ENERGY STARcompliant products. EPA and DOE activities to promote ENERGY STAR evolve over time as markets change and they gain experience in promoting ENERGY STAR ${ }^{2}$.

\section{ENERGY STAR Accomplishments and Challenges}

The ENERGY STAR program has met with considerable success since its inception. In 1999 alone, for instance, Americans purchased more than 100 million ENERGY STARcompliant products (U.S. EPA 2000), representing approximately $20 \%$ market share for compliant products. We review selected accomplishments here, and illustrate instances where the program has needed to respond to changing market conditions.

Office equipment. ENERGY STAR has achieved the greatest market penetration in the office equipment market. Within a few years of the program launch, these labeled products soon dominated the market, largely due to President Clinton issuing Executive Order 12845 requiring that microcomputers, monitors and printers purchased by federal agencies be

\footnotetext{
${ }^{2}$ For up-to-date information about ENERGY STAR, see the program web site at www.energystar.gov. Wilson (1998) summarizes the program's history.
} 
ENERGY STAR-compliant. The sheer size of the federal market pushed manufacturers to participate in the program, and it was relatively easy for consumers to purchase ENERGY STAR-compliant products at the same price as standard products. Now we estimate that $95 \%$ of monitors, $80 \%$ of computers and $99 \%$ of printers sold are ENERGY STAR-compliant. Despite this success, energy savings cannot be achieved if the ENERGY STAR features are not properly activated by the end user. We estimate that only $70 \%$ of the ENERGY STARcompliant office products currently in operation are properly enabled and saving energy. ${ }^{3}$ The ENERGY STAR program has recognized this challenge and implemented several strategies to improve enabling rates, but additional effort will be needed to address this important issue.

Residential Heating and Cooling Equipment. Certain heating and cooling products have gained significant market share. ENERGY STAR-compliant models now comprise more than $30 \%$ of gas furnace sales and more than $20 \%$ of central air conditioner sales. Initially, the program focused its efforts on equipment manufacturers to ensure that ENERGY STARcompliant products were available in the market. More recently, however, EPA has adjusted its program focus to the training of heating and cooling contractors to better sell energyefficient products, because market research indicated that contractors are the key decision influencers in the purchase process. The program is being greatly assisted by state and utility programs that are promoting ENERGY STAR-compliant heating and cooling products through information, training, and financial incentives.

New Homes. As of January 2000, over 14,000 homes have been built to meet the ENERGY STAR guidelines (EPA 2000), exceeding the program goals for number of participating homes, and this number is expected to nearly double by the end of 2000 . The ultimate goal of the program is to have all new homes built in this country meet the ENERGY STAR guidelines, which will require greater participation from large production builders. To achieve this goal, the focus is now on simplifying the program to make it easier and less costly for builders to participate, and increasing consumer awareness of the ENERGY STAR brand in the new home market (Werling et al. 1998).

Commercial Buildings. In 1998, EPA merged the Green Lights program, which had been promoting energy efficient lighting in commercial buildings since 1991, into the ENERGY STAR Buildings and Green Lights Partnership. In 1999, EPA developed a new performance rating system for commercial buildings that allows the most efficient office buildings to earn the ENERGy Star label (Hicks and Clough 1998). More than 100 buildings were awarded the ENERGY STAR label in 1999. As of 2000, the label is available for schools as well. Currently, the ENERGY STAR program is focusing on increasing awareness of the label in the commercial building market, extending the performance rating system to cover additional building types, and working on innovative ways to promote the label, such as measurement and verification criteria for a standard offer.

Major Appliances. The ENERGy StAR program has had some notable successes in the appliance market. ENERGY STAR-compliant clothes washers have exceeded their sales goals by approximately 100\%. Sears sold 750,000 ENERGY STAR-compliant appliances in 1999, and expects to sell at least 1 million units in 2000 (Schlenner 2000). The program focuses on

\footnotetext{
${ }^{3}$ The assumed enabling rate varies by product, from a low of 50\% for PCs to $100 \%$ for fax machines.
} 
working with the regional market transformation collaboratives (described below), while also recruiting and supporting retail program partners. DOE has proposed higher efficiency ENERGY STAR specifications for refrigerators and room air conditioners to take effect when revised Federal efficiency standards become effective in 2000 and 2001, respectively.

Home Electronics. For home electronics, ENERGY STAR focuses on reducing the power consumption of devices when they are not actively in use. Manufacturing partners have actively supported this program, leading to over one thousand ENERGY STAR-compliant TV, VCR, audio, and DVD products on the market. The high visibility of these products with consumers has also greatly aided the promotion efforts for the ENERGY STAR brand. Current program activities in this market include working with retail partners to promote these products, and revising the specification for TVs and VCRs (in collaboration with the manufacturing partners) to modify the allowable standby power levels.

Windows. The ENERGy STAR windows market share has rapidly increased in certain regions of the country. In the Pacific Northwest, programs run by the Northwest Energy Efficiency Alliance (NEEA) and utilities have increased the market share of energy-efficient residential windows from an estimated $10 \%-15 \%$ in 1997 to $44 \%$ in 1999 . NEEA projects ENERGY STAR market share of nearly $60 \%$ by the end of 2000 (quantec 2000). In other areas where the market for efficient windows is less developed, such as Florida, ENERGY STAR windows are gaining market share more slowly. The ENERGY STAR program is working with the Efficient Windows Collaborative ${ }^{4}$ to promote efficient windows in these areas.

Residential and Commercial Lighting. Energy efficient residential light fixtures, commercial exit signs, and screw-in compact fluorescent lamps are all eligible for the ENERGY STAR label. In 1999, nearly 7 million ENERGY STAR-labeled residential fixtures were sold, exceeding the program goals. Likewise, ENERGY STAR-labeled exit signs now comprise about $50 \%$ of exit sign sales, and are expected to continue gaining market share.

Other Commercial-Sector Products. Commercial, industrial, and utility distribution transformers, as well as "cool" (high reflectivity) roofing materials are also eligible for the ENERGY STAR label. The ENERGY STAR program has had mixed success in promoting these products. In the case of transformers, restructuring of the utility industry has made it difficult to interest utility partners in purchasing more efficient products, but efficient commercial and industrial transformers have seen considerable market share increase. This success has largely been due to a product standard in Massachusetts and a building code in Minnesota requiring ENERGY STAR-compliant transformers. For commercial roofing, there have been some successful field trials of ENERGY STAR products, but most roofing specifiers and contractors are not aware of these products or do not see that the benefits outweigh the costs of using an unfamiliar product (Schmeltz and Bretz 1998). EPA is developing information, software tools, and other strategies to address this situation.

Institutional Purchasing. For several years, EPA has been working with the Federal Energy Management Program (FEMP), the General Services Administration (GSA), state and local governments, and other large purchasers to include ENERGY STAR in purchasing

\footnotetext{
${ }^{4}$ A collaborative effort of DOE, the Alliance to Save Energy, and the window industry.
} 
specifications (Dolin and Raynolds 1998). FEMP undertook several initiatives that make it easier for Federal purchasing agents to choose ENERGY STAR, such as identifying ENERGY STAR-compliant products in the GSA catalogs and producing materials to explain the benefits of energy efficient products to purchasers. FEMP is also working with the ENERGY STAR program to label additional products that are commonly purchased in the institutional sector.

International Agreements. Over the last five years EPA has licensed the ENERGY STAR trademark to several countries, including Japan, New Zealand, Australia, and Taiwan. Licensing agreements are currently pending with the European Union and Canada. In addition, EPA maintains ongoing discussions with other countries that may adopt elements of the ENERGY STAR program. These international agreements are driven largely by the fact that many products promoted by ENERGY STAR are sold in global markets and manufactured by global corporations, thus a multinational program is the most effective approach.

\section{The EnERgy STAR Brand}

The goals of the ENERGY STAR program are ambitious. Ultimately, EPA and DOE hope to change the standard way that energy-consuming equipment is purchased and buildings are built, operated, and renovated in this country. This far-reaching goal cannot be achieved simply through the actions of two Federal agencies, but rather requires the assistance and participation of market players and policy makers throughout the country. From its inception, the ENERGY STAR program has worked closely with partners such as manufacturers, homebuilders, building owners, and building contractors to help implement the program and carry the ENERGY STAR message. Increasingly in the last two years, however, the program has enlisted additional allies to help market the brand and achieve its energy and pollution goals. It is helpful to think of this alliance as a national program "platform" that integrates and leverages other national, regional and local efforts. The platform in this case is the ENERGY STAR brand. This collaborative program implementation requires more effort (compared to a program that only involved EPA or DOE efforts) at the national level to ensure consistency and coordination in all marketing efforts.

With the evolving use of the ENERGY STAR brand, EPA and DOE have conducted a brand audit to identify the strengths and weaknesses of the brand and develop a strategy to increase the brand's effectiveness. The audit involved market research to determine how the brand is perceived by consumers. This has also provided a foundation for a planning process within the ENERGY STAR program to determine the future brand strategy. The brand audit found $30 \%$ awareness of the ENERGY STAR brand (without visual prompting), but low understanding about what the brand actually means (Vargas 2000). The brand audit also found a high rate of claimed influence on purchases, among those who recognized the brand, and a high degree of knowledge about the brand among program allies. The area of concern revealed by the audit was a low awareness of the brand among the media. In summary, the audit found no major inconsistencies in the message being publicized in the various markets, and the ENERGY STAR branding efforts are generally on track. The challenge facing the program is to make the brand understandable and relevant to consumers, and improve the media's awareness and perception of the brand.

In light of these findings, EPA and DOE are in the midst of updating their brand strategy. The preliminary results from this process include the following goals. In the next one to two 
years, the goals for the brand are: 1) to have consistency in the brand message publicized by EPA, DOE, and program partners, 2) develop a standard for consistent graphical display of the ENERGY STAR logo to use in its communications, and 3) to increase consumer awareness and relevance by five to ten percentage points. In the longer term, the goal is for greater consistency among all the program partners so that ENERGY STAR appears to be one, unified campaign, and one brand is used in all product markets.

\section{Synergy With Other Partnerships and Programs}

Given a confluence of factors, such as electricity restructuring and a general shift to market transformation programs, the ENERGY STAR program has the opportunity for more partnerships to reach consumers directly. Some of these partnerships are formal agreements, in which EPA, DOE, and other institutions directly coordinate their programs. In other cases, the "partnership" is implicit, and the only interaction happens in the marketplace. In this way, ENERGY STAR can be seen as part of a broad array of methods for market transformation, which are most effective in combination. Table 1 reviews the various energy efficiency partnerships and programs that interact with ENERGY STAR and the mutual benefits they bring to and derive from the program.

Foremost among these partnerships are the regional market transformation collaboratives that have been formed to administer the energy-efficiency public benefits charges authorized as part of many states' electricity market restructuring. These collaboratives exist in California, the Pacific Northwest, the Northeast, and recently one has been formed in the Midwest ${ }^{5}$. In fact, EPA provided seed funding to start the Northeast Energy Efficiency Partnership, and DOE has provided support for the new Midwest collaborative. In total, these collaboratives spend hundreds of millions of dollars on energy efficiency each year, a significant portion of which is being used to promote ENERGY STAR products. This partnership between the Federal government and the regional organizations is particularly complementary because the regional groups can employ program mechanisms (such as rebates) that are not available to the Federal government. Moreover, the majority of purchase decisions regarding energy-using equipment are made locally, and local institutions (such as utilities, governments, non-profits, etc.) are most appropriately placed to influence these decisions. The Federal government brings to this partnership a national brand that amplifies the effectiveness of local and regional programs, as well as an array of marketing materials, and an active "platform" upon which to build their programs.

\footnotetext{
${ }^{5}$ We include in the category of regional collaboratives the work of the Consortium for Energy Efficiency (CEE) and independent utilities that are not members of the regional collaboratives. Originally founded in 1994 to coordinate DSM programs among member utilities, CEE now plays a leading role in coordinating market tranformation programs among the regional collaboratives and utilities.
} 
Table 1. Synergistic Relationship Between ENERGY STAR and Other Energy-Efficiency Partnerships and Programs

\begin{tabular}{|l|l|l|}
\hline \multicolumn{1}{|c|}{ Program } & \multicolumn{1}{c|}{$\begin{array}{c}\text { Advantages Provided to ENERGY } \\
\text { STAR }\end{array}$} & \multicolumn{1}{c|}{$\begin{array}{c}\text { Advantages for Other } \\
\text { Program }\end{array}$} \\
\hline $\begin{array}{l}\text { Regional market } \\
\text { transformation } \\
\text { collaboratives and utility } \\
\text { programs }\end{array}$ & $\begin{array}{l}\text { Promote ENERGY STAR in the } \\
\text { marketplace with marketing, } \\
\text { training, rebates, etc. }\end{array}$ & $\begin{array}{l}\text { National brand marketing } \\
\text { campaign; consistent } \\
\text { program efficiency } \\
\text { specifications }\end{array}$ \\
\hline $\begin{array}{l}\text { Federal Energy } \\
\text { Management Program }\end{array}$ & $\begin{array}{l}\text { Instrumental in getting Executive } \\
\text { Orders promoting ENERGY STAR; } \\
\text { Working to integrate ENERGY STAR } \\
\text { into federal purchasing system }\end{array}$ & $\begin{array}{l}\text { Eases process of setting } \\
\text { purchasing specs.; } \\
\text { provides identifiable } \\
\text { brand in Federal } \\
\text { purchasing market }\end{array}$ \\
\hline $\begin{array}{l}\text { Federal energy RD\&D } \\
\text { programs }\end{array}$ & $\begin{array}{l}\text { Demonstrate technologies that cost- } \\
\text { effectively meet ENERGY STAR } \\
\text { guidelines (larger pool of ENERGY } \\
\text { STAR -compliant products and } \\
\text { processes) }\end{array}$ & $\begin{array}{l}\text { Provides path for market } \\
\text { adoption of technologies } \\
\text { beyond the demonstration } \\
\text { phase }\end{array}$ \\
\hline $\begin{array}{l}\text { Federal appliance } \\
\text { standards }\end{array}$ & $\begin{array}{l}\text { Standard test procedures; reference } \\
\text { efficiency levels for some ENERGY } \\
\text { STAR products }\end{array}$ & $\begin{array}{l}\text { Initial market experience } \\
\text { with energy-efficient } \\
\text { products and technologies }\end{array}$ \\
\hline Building codes & $\begin{array}{l}\text { Prescriptive codes could specify } \\
\text { ENERGY STAR levels for some } \\
\text { building components; Model Energy } \\
\text { Code provides baseline for ENERGY } \\
\text { STAR homes }\end{array}$ & $\begin{array}{l}\text { Near 100\% code } \\
\text { compliance for ENERGY } \\
\text { STAR homes and } \\
\text { buildings; referencing } \\
\text { ENERGY STAR simplifies } \\
\text { code writing }\end{array}$ \\
\hline \multicolumn{2}{|l}{} \\
\hline
\end{tabular}

ENERGY STAR also has a strong relationship with several other Federal energy programs. Technology research, development, and demonstration (RD\&D) programs (such as DOE's Building America) provide a steady stream of demonstrated energy-efficiency technologies, thus expanding the choice and driving down the price of ENERGY STAR products. On the other end of the market diffusion curve, the Federal appliance standards program serves as a reference efficiency level for some ENERGY STAR products, thus simplifying the development of ENERGY STAR specifications. Also, while it is not a stated goal of the ENERGY STAR program, we believe that several of the recently announced Federal standard updates (such as clothes washers) have been facilitated by the existence of an ENERGY STAR specification for those products.

Finally, we note the potential for a mutually supportive relationship between the Federal ENERGY STAR program and national, state, and local building codes. Thus far, this relationship has been limited to the ENERGY STAR new homes guidelines being indexed to the national Model Energy Code. In the future, it is possible that building codes could simplify some prescriptive requirements by requiring ENERGY STAR-compliant products, while code compliance would be improved for buildings receiving the ENERGY STAR label. 


\section{Program Evaluation}

The ENERGY STAR program has been in place long enough to warrant evaluation for several of the product categories. Formal evaluations are being planned or conducted for office equipment, residential heating and cooling equipment, new homes, and a retrospective evaluation of the Green Lights program. In addition, DOE collects sales tracking data from the retail partners on an ongoing basis, allowing measurement of market share impacts for appliances and other retail products. The evaluation studies will be used to verify savings claims, improve the accuracy of future savings estimates, and improve program design.

In general, the program evaluations are focusing on market impacts of the ENERGY STAR program rather than energy savings impacts. Market impacts are measured either through direct market effects (e.g., market share data collected from partners) or proximal measures (e.g., partner perceptions of the program or stated purchasing behavior). Attribution of impacts will be an important evaluation result for some products (such as Green Lights), while for other products (such as office equipment) the gross impact is the most important result. Energy savings impacts will be measured for two products. For new homes, a billing analysis will be conducted to determine the energy performance of energy efficient homes in the field, compared to a sample of standard new homes. For office equipment, a survey of end-users was conducted to determine operating patterns and the enabling rates for ENERGY STAR features, and office equipment will be monitored in the field to verify energy savings.

In addition to the EPA and DOE evaluations, the regional collaboratives are evaluating many of their programs that promote ENERGY STAR. Because the collaboratives and utilities are spending public benefits charge funds to promote ENERGY STAR, they usually must quantify the impact of the program to justify the expenditures to state regulatory and legislative bodies. EPA and DOE will draw on these regional evaluations to assist in their own evaluation process. In addition, EPA and CEE have made an effort to coordinate these regional and national evaluation efforts, in order to reduce costs and maximize effectiveness.

\section{Future developments}

This section describes some of the ways that the ENERGY STAR program may evolve over the next few years. These are not firm plans, but simply illustrate ways that ENERGY STAR might respond to trends in the marketplace.

EPA and DOE continue to explore additional products for labeling, in order to expand the scope of the ENERGY STAR program. In general, products are selected based on their potential for significant energy savings, the receptiveness of the industry, the potential for collaboration with other partners, and the visibility of the product with consumers (Sanchez and Fanara 2000). Currently, EPA is finalizing ENERGY STAR specifications for set-top boxes, ventilation fans, water coolers, and traffic signals. Additional specifications are expected in the next year for commercial reach-in refrigerators, ceiling fans, residential dehumidifiers, commercial unitary HVAC equipment, industrial motors, and wall-pack transformers. Although extension of the brand appears to be an easy way to achieve additional energy savings, this desire needs to be balanced with the reality of EPA and DOE's ability to administer the programs effectively given limited staffing, and the need to keep the brand focused on products that perform well and deliver significant savings. Additionally, some have argued over the years that ENERGY STAR should become a broader 
environmental label, for instance, to promote green power. For the foreseeable future, however, EPA and DOE plan to keep the program focused on energy efficiency. This focus maintains the integrity of the brand in the consumer's mind, and is also consistent with the enabling legislation (1990 Clean Air Act Amendments) under which the program operates.

From its inception, ENERGY STAR has been known best for labeling products. However, this approach ignores the need to address buildings as systems, rather than simply components, in order to maximize energy savings and other benefits from energy efficiency upgrades. For ENERGY STAR, this requires "integrating" strategies that encourage building owners to systematically upgrade their buildings rather than taking a piecemeal approach. The ENERGY STAR Buildings program was designed this way from the start, and its use of a whole-building benchmarking tool gives building owners an incentive to meet the criteria in the most cost-effective way, usually requiring an analysis of the building as a system. Likewise on the residential side, for New Homes the ENERGY STAR label is awarded based on reductions in consumption for several end uses. In the home improvement market, EPA is developing an ENERGY STAR Home Improvement Program that will encourage homeowners to take a systematic approach to upgrading their home's energy efficiency. The program will involve many strategies, including a consumer web site providing customized recommendations about what upgrades make sense in a given house. EPA is exploring various options for setting labeling criteria for existing homes, including a whole-house benchmarking tool similar to that for commercial buildings, but the program design has not been finalized. Challenges that all these integrating programs need to address are a lack of market infrastructure for whole-building upgrades, a tendency for building owners to focus on component upgrades as a sufficient solution, and a lack of confidence on the part of building owners that the promised benefits (energy and non-energy) will be realized.

Another "integration" strategy that ENERGY STAR may pursue in the future is crossmarketing packages of individual products. For instance, an "ENERGY STAR kitchen" campaign would jointly promote the ENERGY STAR-labeled products found in kitchens. The New York State Energy Research and Development Agency (NYSERDA) has developed and is piloting a program to do just this. A cross-marketing program has the potential to increase sales of ENERGY STAR products because product purchases tend to happen in clusters at important points in a building's life-cycle, such as initial occupation, a change in ownership, or renovation. Purchasers may be amenable to selecting multiple ENERGY STAR-labeled products at one time, although this concept needs to be verified through market testing.

Another example of extending the ENERGY STAR brand beyond just products is the idea of labeling services, such as air duct sealing. As a component of its ENERGY STAR Home Improvement Program, EPA has developed a specification for energy efficient ducts. This program is different from other labeled products in that ducts are a house component that are site-assembled and exhibit great variation in energy performance from house to house. Thus, an effective specification must include on-site performance duct performance testing. This differs significantly from the other ENERGY STAR product specifications, which are usually based on laboratory testing protocols applied to manufactured products. EPA will pilot test the ENERGY STAR duct label over the next few months. Additional services, such as building air sealing, will be considered for future labeling.

Finally, the ENERGY STAR program will work to strengthen its existing partnerships and build new alliances in the future. A big part of this effort will be to improve coordination with the regional market transformation collaboratives and local utility market 
transformation programs. Better coordination on current and proposed program design is needed, as well as collaboration on program evaluation.

\section{Summary}

In eight years, ENERGY STAR has grown from a program focusing on personal computers to a multinational program promoting over 30 products across commercial and residential markets, with thousands of program partners. Over this time, ENERGY STAR has become a brand recognized by a significant number of consumers, as well as a collaborative effort that is uniting a variety of separate market transformation programs. The success of ENERGY STAR thus far is due in equal part to the vision and guidance of EPA and DOE, and the hard work of the program partners-manufacturers, retailers, contractors, builders, building owners, utilities, and industry allies. In the future, EPA and DOE hope to increase the program's energy savings by increasing the strength of the brand, labeling new products, and improving the program mechanisms and alliances.

\section{Acknowledgments}

We would like to thank Maria Vargas of the U.S. EPA Climate Protection Division and Bill Noel of the U.S. DOE for their input and review of this paper. This work was supported by the Office of Atmospheric Programs, Climate Protection Division of the U.S. Environmental Protection Agency. Prepared for the U.S. Department of Energy under Contract No. DE-AC03-76SF00098.

\section{References}

Dolin, J., and N. Raynolds. 1998. "The Energy Star Purchasing Initiative." In Proceedings of the 1998 ACEEE Summer Study on Energy Efficiency in Buildings, 7:77-87. Washington, DC: American Council for an Energy-Efficient Economy.

Hicks, T., and D. Clough. 1998. "The Energy Star Building Label: Building Performance through Benchmarking and Recognition." In Proceedings of the 1998 ACEEE Summer Study on Energy Efficiency in Buildings, 4:205-210. Washington, DC: American Council for an Energy-Efficient Economy.

quantec. 2000. Market Progress Evaluation Report for the Energy Star Windows Program. 00-046. Portland, Ore.: Northwest Energy Efficiency Alliance. March.

Sanchez, M., and A. Fanara. 2000. "New Product Development: The Pipeline for Future Energy Star Growth." In Proceedings of the 2000 ACEEE Summer Study on Energy Efficiency in Buildings, Volume 7: Washington, DC: American Council for an EnergyEfficient Economy.

Schlenner, J. 2000. Sears Brand Central and Energy Star. Presented at the ACEEE/CEE National Symposium on Market Transformation, Washington, DC, March 20-21. 
Schmeltz, R., and S. Bretz. 1998. "Energy Star Label for Roof Products." In Proceedings of the 1998 ACEEE Summer Study on Energy Efficiency in Buildings, 9:161-172. Washington, DC: American Council for an Energy-Efficient Economy.

U.S. EPA. 2000. The Power to Make a Difference: Achievements for 1999 - In Brief. Washington, DC: U.S. Environmental Protection Agency, Climate Protection Division. March.

Vargas, M. 2000. Using Energy Star Program Market Research to Improve Consumer Outreach. Presented at the ACEEE/CEE National Symposium on Market Transformation, Washington, DC, March 20-21.

Werling, E., J. D. Hall, D. Meisegier, S. Rashkin, B. Collison, and G. Chinery. 1998. "Lessons Learned in the Energy Star Homes Program." In Proceedings of the 1998 ACEEE Summer Study on Energy Efficiency in Buildings, 2:243-257. Washington, DC: American Council for an Energy-Efficient Economy.

Wilson, A. 1998. "ENERGY STAR Programs: Uncle Sam's Partnerships for Energy Efficiency". Environmental Building News. June. p. 1. 